\section{Influenza A(H5N6) Virus Reassortant, Southern China, 2014}

\section{Hanqin Shen, ${ }^{1}$ Boliang Wu, ${ }^{1}$ Yimin Chen, Yingzuo Bi, Qingmei Xie}

Author affiliations: South China Agricultural University, Guangzhou, China (H. Shen, B. Wu, Y. Chen, Y. Bi, Q. Xie); Key Laboratory of Animal Health Aquaculture and Environmental Control, Guangzhou (H. Shen, Q. Xie); Ministry of Agriculture, Guangzhou (B. Wu, Q. Xie); South China Collaborative Innovation Center for Poultry Disease Control and Product Safety,

Guangzhou (Q. Xie)

DOI: http://dx.doi.org/10.3201/eid2107.140838

To the Editor: Avian influenza A viruses generally do not cause disease in aquatic birds, the natural reservoir of these viruses (1). Influenza A(H5N6) was first isolated from mallards by García et al. in 1975 (2). Influenza viruses continue to evolve and reassort to generate novel, highly pathogenic viruses. Novel H5 highly pathogenic avian influenza virus subtypes, such as H5N2, H5N5, and $\mathrm{H} 5 \mathrm{~N} 8$, have been reported $(3,4)$. Highly pathogenic influenza A viruses are endemic to many countries (http://www.oie.int/en/animal-health-in-the-world/update-on-avian-influenza/2015/), cause tremendous economic losses to the poultry industry, and represent a serious threat to public health.

In March 2014, an influenza A(H5N6) outbreak caused the death of 457 birds in Laos (http://www.oie. int/wahis_2/public $\% 5$ C.. $\% 5$ Ctemp $\% 5$ Creports/en imm_0000015052_20140507_182757.pdf). During the same month, a flock of ducks in Guangdong Province in southern China exhibited typical respiratory signs of influenza A virus infection. This flock also had $70 \%$ decreased egg production and a slightly increased mortality rate. Throat swab specimens were taken from the symptomatic and dead ducks, and the samples were used to inoculate chicken embryos for virus isolation. Hemagglutination (HA) and neuraminidase (NA) inhibition assays were performed to identify the subtype of the isolated virus, which was designated A/duck/Guangdong/GD01/2014 (H5N6) (GD01/2014). The complete RNA genome was amplified by reverse transcription PCR and cloned into the pMD-19T vector for sequencing (5). The complete genome sequence of the GD01/2014 virus was submitted to GenBank (accession nos. KJ754142-KJ754149).

Multiple-sequence alignments showed that the HA gene of GD01/2014 shared $97.5 \%$ nt identity with A/ wild duck/Shandong/628/2011 (H5N1) and NA genes

${ }^{1}$ These authors contributed equally to this article. shared $96.6 \%$ and $98.3 \%$ nt identity with $\mathrm{A} /$ swine/Guangdong/K6/2010 (H6N6) and A/duck/Shantou/1984/2007 (H6N6), respectively. All internal genes shared high levels of nucleotide identity $(97.6 \%-98.5 \%)$ with A/wild duck/ Fujian/2/2011(H5N1). The whole genes of GD01/2014 and the H5N6 viruses in Laos (LAO/2014) shared $98.2 \%-99.7 \%$ nt identity, indicating the same genotype. Phylogenetic analysis of the HA gene revealed that the isolated virus belonged to clade 2.3.4.6 (online Technical Appendix Figure, panel A, http://wwwnc.cdc.gov/EID/ article/21/7/14-0838-Techapp.pdf) (6). The NA gene of GD01/2014 was clustered with some H6N6 viruses circulating in China (online Technical Appendix Figure, panel B). The 6 internal genes of GD01/2014 were closely related with A/wild duck/Fujian/2/2011(H5N1) and A/wild duck/Fujian/1/2011(H5N1) (online Technical Appendix Figure, panels $\mathrm{C}-\mathrm{H}$ ). Phylogenetic analysis showed that all 8 genes of GD01/2014 and LAO/2014 were closely related although genetically distant from the earlier isolated H5N6 viruses (online Technical Appendix Figure). These findings suggest that GD01/2014 and LAO/2014 are reassortants of wild duck $\mathrm{H} 5 \mathrm{~N} 1$ and $\mathrm{H} 6 \mathrm{~N} 6$ viruses, both of which have pathogenic and potential pandemic capacity in southern China. A previous report that $\mathrm{H} 5 \mathrm{~N} 1$ and H6N6 co-infected a duck suggests that GD01/2014 might be generated from the co-infection of $\mathrm{H} 5 \mathrm{~N} 1$ and $\mathrm{H} 6 \mathrm{~N} 6$ in the same host (7).

The intravenous pathogenicity index of GD01/2014 was 3.0, which indicates that the isolate is highly pathogenic for chickens. GD01/2014 had multiple basic amino acids (LRERRRKR/GLF) at the cleavage site between HA1 and HA2; this characteristic is typical of highly virulent influenza viruses (8). The HA protein contained E190, R220, G225, Q226, and G228 (H3 numbering) residues at the receptor-binding pockets, indicating that the virus preferentially binds to the sialic acid-2,3-NeuAcGal of the avian-like receptor (9). The HA protein has 7 potential N-glycosylation sites (PGSs); the HA1 protein has 5 PGSs; the HA2 protein has 2 PGSs. The NA protein of GD01/2014 and LAO/2014 had a deletion of 11 aa residues at positions 59-69 (N6 numbering) in the NA stalk region. Moreover, a deletion of 5 aa residues from positions $80-84$ in the nonstructural 1 protein was found in GD01/2014 and LAO/2014. The position 627 and 701 of the polymerase basic 2 protein were $\mathrm{E}$ and $\mathrm{D}$, respectively, characteristics of the avian influenza virus (10)

In summary, in 2014, outbreaks of H5N6 virus occurred in China, Laos, and Vietnam and caused the deaths of infected humans in Sichuan province, China (http://www.oie.int/en/animal-health-in-the-world/updateon-avian-influenza/2014/; http://www.wpro.who.int/china/ mediacentre/releases/2014/20140507/en/). We characterized the novel reassortant H5N6 virus in China and found that it 
was the same genome type as and was highly homologous with the H5N6 virus in Laos. The findings in this study are also supported by the previous genetic characterization of these viruses by Wong et al. (11). However, the adaptation, host range, and virulence of this reassortant H5N6 virus are still unclear and should be further investigated. Furthermore, the potential for infection, outbreaks, and pandemic in other poultry and mammals should be carefully monitored.

This work was supported by the National Modern Agricultural Industry Technology System Project of China (CARS-41) and by the Technology Planning Project of Guangdong Province of China (grant nos. 2012B020306002 and 2012B091100078).

\section{References}

1. Chen H, Deng G, Li Z, Tian G, Li Y, Jiao P, et al. The evolution of H5N1 influenza viruses in ducks in southern China. Proc Natl Acad Sci U S A. 2004;101:10452-7. http://dx.doi.org/10.1073/ pnas.0403212101

2. García M, Suarez DL, Crawford JM, Latimer JW, Slemons RD, Swayne DE, et al. Evolution of H5 subtype avian influenza A viruses in North America. Virus Res. 1997;51:115-24. http://dx.doi.org/10.1016/S0168-1702(97)00087-7

3. Zhao K, Gu M, Zhong L, Duan Z, Zhang Y, Zhu Y, et al. Characterization of three $\mathrm{H} 5 \mathrm{~N} 5$ and one $\mathrm{H} 5 \mathrm{~N} 8$ highly pathogenic avian influenza viruses in China. Vet Microbiol. 2013;163:351-7. http://dx.doi.org/10.1016/j.vetmic.2012.12.025

4. Zhao G, Gu X, Lu X, Pan J, Duan Z, Zhao K, et al. Novel reassortant highly pathogenic $\mathrm{H} 5 \mathrm{~N} 2$ avian influenza viruses in poultry in China. PLoS ONE. 2012;7:e46183. http://dx.doi.org/ 10.1371/journal.pone.0046183

5. Hoffmann E, Stech J, Guan Y, Webster RG, Perez DR. Universal primer set for the full-length amplification of all influenza A viruses. Arch Virol. 2001;146:2275-89. http://dx.doi.org/10.1007/s007050170002

6. Gu M, Zhao G, Zhao K, Zhong L, Huang J, Wan H, et al. Novel variants of clade 2.3.4 highly pathogenic avian influenza A(H5N1) viruses, China. Emerg Infect Dis. 2013;19:2021-4. http://dx.doi.org/10.3201/eid1912.130340

7. Liu Z, Xu B, Chen Q, Chen Z. Complete genome sequence of a mixed-subtype (H5N1 and H6N6) avian influenza virus isolated from a duck in Hunan Province, China. Genome Announc. 2014;2:e00310-4. http://dx.doi.org/10.1128/genomeA.00310-14

8. Steinhauer DA. Role of hemagglutinin cleavage for the pathogenicity of influenza virus. Virology. 1999;258:1-20. http://dx.doi.org/10.1006/viro.1999.9716

9. Stevens J, Blixt O, Tumpey TM, Taubenberger JK, Paulson JC, Wilson IA. Structure and receptor specificity of the hemagglutinin from an H5N1 influenza virus. Science. 2006;312:404-10. http://dx.doi.org/10.1126/science.1124513

10. Li Z, Chen H, Jiao P, Deng G, Tian G, Li Y, et al. Molecular basis of replication of duck $\mathrm{H} 5 \mathrm{~N} 1$ influenza viruses in a mammalian mouse model. J Virol. 2005;79:12058-64. http://dx.doi.org/10.1128/JVI.79.18.12058-12064.2005

11. Wong FYK, Phommachanh P, Kalpravidh W, Chanthavisouk C, Gilbert J, Bingham J, et al. Reassortant highly pathogenic influenza A(H5N6) virus in Laos. Emerg Infect Dis. 2015;21:511-6. http://dx.doi.org/10.3201/eid2103.141488

Address for correspondence: Qingmei Xie, College of Animal Science, South China Agricultural University, 483 Wushan St, Guangzhou 510642, China; email: qmx@scau.edu.cn

\section{Characterization of 3 Megabase-Sized Circular Replicons from Vibrio cholerae}

\section{Kazuhisa Okada, Wirongrong Natakuathung, Mathukorn Na-Ubol, Amonrattana Roobthaisong, Warawan Wongboot, Fumito Maruyama, Ichiro Nakagawa, Siriporn Chantaroj, Shigeyuki Hamada}

\author{
Author affiliations: Thailand-Japan Research Collaboration \\ Center on Emerging and Re-emerging Infections, Nonthaburi, \\ Thailand (K. Okada, W. Natakuathung, M. Na-Ubol, \\ A. Roobthaisong, W. Wongboot, S. Hamada); Osaka University, \\ Osaka, Japan (K. Okada, S. Hamada); Tokyo Medical and \\ Dental University, Tokyo, Japan (F. Maruyama, I. Nakagawa); \\ National Institute of Health, Nonthaburi (S. Chantaroj)
}

DOI: http://dx.doi.org/10.3201/eid2107.141055

To the Editor: Prokaryotes typically have a single circular chromosome. However, some bacteria have $>1$ chromosome. Vibrio bacteria, for example, have 2 circular chromosomes: 1 (Ch1) and 2 (Ch2) (1-3). Most recognizable genes responsible for essential cell functions and pathogenicity are located on Ch1. Ch2 is also thought to encode some genes essential for normal cell function and those associated with virulence. Both chromosomes are controlled coordinately in their replication and segregation (4). Evidence suggests that $\mathrm{Ch} 2$ was originally a mega-plasmid captured by an ancestral Vibrio species $(2,5)$. We report the characterization of recent isolates of $V$. cholerae $\mathrm{O} 1$ from Thailand that carry a novel gigantic replicon (Rep.3) in addition to $\mathrm{Ch} 1$ and $\mathrm{Ch} 2$.

Cholera outbreaks occurred in Tak Province, Thailand, during March-December 2010. We obtained 118 isolates of $V$. cholerae $\mathrm{O} 1$ and subjected their NotI digests to pulsedfield gel electrophoresis (PFGE), which differentiated the isolates into 8 different patterns (6). The profile of PFGE type A6 was identical to that of PFGE type A4, except that a large DNA band existed in type A6. The PFGE profile of the intact (undigested) DNA of the type A6 isolates exhibited a unique genome structure consisting of 3 large replicons (Figure, http://wwwnc.cdc.gov/EID/article/21/7/14-1055-F1.htm).

Three isolates of PFGE type A6 (TSY216, TSY241, and TSY421) were obtained during June 3-July 5, 2010, from 3 unrelated residents of a village near the ThailandMyanmar border. The isolates were classified as multilocus variable-number tandem-repeat analysis type 16 , suggesting that they are of clonal origin (6). Next, we performed whole-genome sequencing of TSY216, as a representative of PFGE type A6 isolates, by using the GS FLX Titanium 